\title{
The prevalence of orthodontic treatment needs of school children in northern Herzegovina
}

\author{
Ružica Zovko ${ }^{1}$, Stipo Cvitanović ${ }^{2}$, Mirela Mabićs ${ }^{3}$ Anka Ćorić ${ }^{1}$, Katarina Vukojević ${ }^{4}$, \\ Kristina Goršeta ${ }^{5}$, Domagoj Glavina ${ }^{5}$
}

${ }^{1}$ Health Care Center, Mostar, Bosnia and Herzegovina, ${ }^{2}$ Health Care Center Prozor-Rama, Bosnia and Herzegovina ${ }^{3}$ Faculty of Economics, University of Mostar, Bosnia and Herzegovina, ${ }^{4}$ Study Program of Dental Medicine, School of Medicine, University of Mostar, Bosnia and Herzegovina, ${ }^{5}$ Faculty of Dentistry University of Zagreb, Croatia

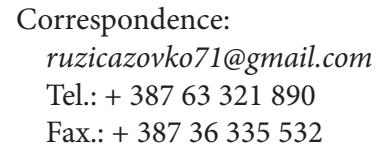

Received: 13 March 2017

Accepted: 19 May 2017

Key words: Orthodontic treatment Dental Health Component - Index of Orthodontic Treatment Need • Bosnia and Herzegovina.

\begin{abstract}
Objective. The study was conducted to evaluate the Index of Orthodontic Treatment Need based on the Dental Health Component (DHC). Materials and methods. 300 students aged 12-15 years were included in this study. The examinations were performed in two elementary schools in the municipality of Prozor-Rama, using standard dental instruments. Children were ranked into five grades according to the DHC. Results. Only $12 \%$ of children were found not to have a need for orthodontic treatment. Of the others, $45.33 \%$ had a great, and $10 \%$ a very great need for orthodontic treatment. The rest of the children were found to have a need for minor or moderate orthodontic treatment. Slightly more girls than boys had a great or a very great need for treatment, although the difference by gender was not statistically significant. Analysis of the level of need by age of children showed no significant difference; children with a great need of orthodontic treatment prevailed in all age groups. About $85 \%$ of children with a great and a very great need for orthodontic treatment would agree to orthodontic treatment, while the rate of non-acceptance was about $5 \%$. Conclusion. The high rate of need for orthodontic treatment in the examined students is explained by the lack of programs for this type of health care, the insufficient number of qualified orthodontic specialists, and the very low percentage of allocations from the state budget for oral health.
\end{abstract}

\section{Introduction}

Dentofacial anomalies are conditions in which there is a deviation from the normal morphology, size and function of individual parts or the whole of the craniofacial complex (1). Consequences of disorders related to dentofacial anomalies are numerous, from oral function disorders to disrupted facial aesthetics, which is a serious public health problem. Orthodontic anomalies, especially dental arch crowding, lead to the rapid formation of caries and periodontal diseases.
In displaced teeth, even impeccable oral hygiene cannot eliminate food residues left in retention spaces, resulting in fermentation processes, the products of which are acids that lead to damage to the dental substance and supporting apparatus of the teeth $(2,3)$.

Many studies have pointed out that there is a correlation between orthodontic anomalies and periodontal conditions (4). Today, in countries with a well-developed health care system, longitudinal studies examining the prevalence and registering of dentofacial anomalies are conducted in children from 
the age of three years. Timely implementation of orthodontic treatment is planned in this way $(5,6)$.

The objective of epidemiological studies in orthodontics is to determine the incidence and prevalence of malocclusions and identify variations in different population groups, and thus to establish priorities in implementation of orthodontic treatment in children (7). Orthodontic anomalies impair normal performance of the orofacial complex functions (mastication, deglutition and phonation), and compromise facial aesthetics (8). Distinct orthodontic anomalies, accompanied by impaired facial aesthetics and disturbed oral functions, particularly of speech, significantly affect the emotional and social development of both children and adults $(9,10)$.

Children with orthodontic anomalies may become introvert and avoid social contact, and often these children become the subject of ridicule and teasing by their peers (11).

Orthodontic anomalies assume epidemic proportions in the world, even in the countries with well-developed oral health care. In determining the prevalence, diagnostics based on standardized criteria are important in order to identify treatment priorities. This is successfully achieved by the Index of Orthodontic Treatment Need (IOTN) using the Dental Health Component (DHC) $(12,13)$.

IOTN identifies the various percentages of these needs. For example, in Italy 59.5\% of elementary school children have a need for orthodontic treatment (12), in children aged 12-14 years in the United Kingdom this need ranges from $15-26 \%$ (13), in children aged 8-16 years in Sweden this need is 28.9\% (14), in Germany $26.2 \%$ of the examined children need orthodontic treatment (15) and in Malaysia $47.9 \%$ (16). Similar studies on the state of orthodontic anomalies, in terms of the need for orthodontic treatment, have been carried out in a wider area of the Western Balkans (17). The last study conducted in Bosnia and Herzegovina was in 1988, before the war. The subjects were children aged 6-15 years, and orthodontic anomalies were established in $36.7 \%$ of subjects, while $30 \%$ were in need of orthodontic treatment (17). These studies did not use the IOTN according to the DHC, which is now the new standard of categorization of orthodontic treatment (3-5).

This was the motive for new research aimed at establishing the real need for orthodontic treatment and the readiness of children to agree to orthodontic treatment.

\section{Materials and methods}

The study was conducted in two elementary schools in the municipality of ProzorRama, Bosnia and Herzegovina. The study included a total of 300 randomly selected students from 12 to 15 years of age: 12 years of age - $78(26.0 \%), 13$ years - $73(24.3 \%), 14$ years - $76(25.3 \%)$ and 15 years - $73(24.3 \%)$. The genders were equally represented in the sample (150 girls and 150 boys). All school children from both surveyed schools who were younger than 12 or older than 15 years of age, as well as children who had received orthodontic treatment before these examinations, or who were undergoing orthodontic treatment during these examinations, were excluded from the study.

The first phase of the research was carried out at the Rama Community Health Center in Prozor with the approval of the Ministry of Education, Science, Culture and Sport of the Herzegovina-Neretva County.

The study was approved by the Ethics Committee of the Rama Community Health Center in accordance with the Helsinki Declaration. Informed consent was obtained from the parents. The children were informed about the study in an appropriate way and only those children who agreed to participate were included in the study. The inclusion criteria were age from 12 to 15 
years and a documented medical record, as well as information from the parents, that the child had not had orthodontic treatment before this study. According to the World Health Organization's recommendations, this age group is the most appropriate for oral health examination (18). During this period, children enter adolescence, when growth significantly affects the orofacial complex.

Dental health components with dental characteristics were examined according to the checklist of the Swedish Dental Board. This method was used as a reference for determining the orthodontic treatment need based on functional and occlusal characteristics, as recommended by the WHO (10). IOTN according to the DHC is determined by the following characteristics: increased overbite depth, open bite (anterior or lateral), impeded tooth eruption, Class II and III intercuspation, missing teeth, cleft lip and/ or palate $(10,11)$. The patients were classified into five categories accordingly.

The clinical examination was carried out using standard dental instruments, and the necessary measurements were carried out using the millimeter gauge (Dentalschiebelehre). The persons conducting the research were general dentists with several years of experience in their profession, who use IOTN assessment on a daily basis. Two investigators assessed IOTN taking into consideration inter-observer variations.

All data were entered into the research survey, which consisted of two parts. General data on each examined child were entered into the first part of the survey, and the data on function and characteristics of dentition, with an estimation of the index of orthodontic treatment need, into the second part.

Analysis of acceptance of orthodontic treatment was carried out among children found to have a great and very great need for orthodontic treatment (levels 4 and 5). Three options were offered in the following answers: "I agree to orthodontic treatment", "I have no attitude towards treatment", and "I do not agree to orthodontic treatment". The verbal response was entered into the questionnaire. The examination was carried out for both genders.

\section{Statistical analysis}

Data were analyzed in SPSS for Windows (version 17.0., SPSS Inc. Chicago, Illinois, USA) and Microsoft Excel (version Office 2007, Microsoft Corporation, Redmond, WA, USA). Results were expressed in absolute (f) and relative frequencies (\%). The Chi-square $\left(\chi^{2}\right)$ test was used for testing the significance of differences regarding gender and age. In the absence of the expected frequencies, Fisher's exact test was used. The level of significance was $p=0.05$. $P$ values that could not be expressed to three decimal places are shown as $\mathrm{p}<0.001$.

\section{Results}

The subjects were divided according to the need for orthodontic treatment, by gender and by age (Table 1 ).

According to the results, significantly more children (almost 90\%) had a need for orthodontic treatment $\left(\chi^{2}=173.280 ; \mathrm{df}=1\right.$; $\mathrm{p}<0.001)$. The distribution of boys and girls by need for treatment was identical, while the distribution of children of different ages varied slightly $\left(\chi^{2}=0.606 ; \mathrm{df}=3 ; \mathrm{p}=0.895\right)$.

The distribution of children with a need for orthodontic treatment by degree, in total, by gender and by age is shown in Table 2 .

There was a significant difference in the distribution of children who had a need for orthodontic treatment by degree of need $\left(\chi^{2}=103.394 ; \mathrm{df}=3 ; \mathrm{p}<0.001\right)$. Comparison of indices of orthodontic treatment need for boys and girls showed no statistically significant difference $\left(\chi^{2}=1.422 ; \mathrm{df}=3 ; \mathrm{p}=0.700\right)$, although it was shown that girls had a great 
Table 1 Distribution of children by assessed need for orthodontic treatment, in total, by gender and age

\begin{tabular}{|c|c|c|c|c|c|c|c|}
\hline \multirow{3}{*}{$\begin{array}{l}\text { Orthodontic } \\
\text { treatment }\end{array}$} & \multicolumn{7}{|c|}{ Children (n; \%) } \\
\hline & \multirow{2}{*}{ Total } & \multicolumn{2}{|l|}{ Gender } & \multicolumn{4}{|c|}{ Age (years) } \\
\hline & & Boys & Girls & 12 & 13 & 14 & 15 \\
\hline Not needed & $36(12.0)$ & $18(12.0)$ & $18(12.0)$ & $9(11.5)$ & $8(11.0)$ & $11(14.5)$ & $8(11.0)$ \\
\hline Needed & $264(88.0)$ & $132(88.0)$ & $132(88.0)$ & 69 (88.5) & $65(89.0)$ & 65 (85.5) & $65(89.0)$ \\
\hline Total & 300 & 150 & 150 & 78 & 73 & 76 & 73 \\
\hline
\end{tabular}

Table 2 Distribution of children with need for orthodontic treatment by index of need, in total, by gender and age

\begin{tabular}{llllllll}
\hline \multirow{2}{*}{ IOTN } & \multicolumn{7}{l}{ Children (n; \%) } \\
\cline { 2 - 8 } & \multirow{2}{*}{ Total } & Gender & \multicolumn{4}{l}{ Age (years) } \\
\cline { 3 - 8 } & & Boys & Girls & 12 & 13 & 14 & 15 \\
\hline Minor anomaly, no treatment need & $54(20.5)$ & $27(20.5)$ & $27(20.5)$ & $13(18.8)$ & $12(18.5)$ & $15(23.1)$ & $14(21.5)$ \\
Borderline treatment need & $44(16.7)$ & $25(18.9)$ & $19(14.4)$ & $13(18.8)$ & $10(15.4)$ & $12(18.5)$ & $9(13.9)$ \\
Treatment greatly needed & $136(51.5)$ & $64(48.5)$ & $72(54.5)$ & $34(49.3)$ & $37(56.9)$ & $32(49.2)$ & $33(50.9)$ \\
Treatment very greatly needed & $30(11.4)$ & $16(12.1)$ & $14(10.6)$ & $9(13.0)$ & $6(9.2)$ & $6(9.2)$ & $9(13.9)$ \\
\hline Total & 264 & 132 & 132 & 69 & 65 & 65 & 65 \\
\hline
\end{tabular}

IOTN=Index of Orthodontic Treatment Need.

or very great need for treatment slightly more often. Analysis of levels of need by age of children did not show any significant difference $\left(\chi^{2}=2.719 ; \mathrm{df}=9 ; \mathrm{p}=0.974\right)$, children with a great need for orthodontic treatment prevailed in all age subgroups.

Based on the examinations and data analysis, 166 children out of all those included in the study were found to have a great or very great need for orthodontic treatment. Among them, 141 (84.93\%) would agree to treatment, $18(10.84 \%)$ children did not have a personal opinion about treatment, and $7(4.21 \%)$ would not agree to treatment. Children who did not desire treatment, despite their need, explained that they did not care about treatment, while others stated that they did not have the financial resources for the treatment. According to the survey results, $70(81.39 \%)$ boys would agree to orthodontic treatment, 12 (13.95\%) did not have an opinion on this treatment, and $4(4.65 \%)$ would not agree to orthodontic treatment. Out of the total number of girls with a need for orthodontic treatment, 71 $(88.75 \%)$ of them declared that they would agree to treatment, $6(7.5 \%)$ did not have a personal opinion on this treatment, and 3 (3.75\%) would not agree to this treatment.

\section{Discussion}

Determination of orthodontic treatment needs based on assessment of the DHC in children aged 12-15 years in two elementary schools in the municipality of Prozor-Rama, showed that a large number of children have a great and very great need for orthodontic treatment. Almost half of the examined subjects had a great need for orthodontic treatment, while $10 \%$ of the children had a very great need for orthodontic treatment.

This is in accordance with similar studies on orthodontic treatment needs in children performed in Jordan (71\%), Malaysia (47.9\%) and Turkey (40\%) (19-21), indicating a correlation between the socio-economic status of the population and the index 
of orthodontic treatment need (22). Studies have shown that external appearance, including dental appearance and speech, is essential for a person's socialization, which is why orthodontic anomalies negatively affect the social development of children (23). Introducing more reliable statistical records and monitoring outcomes of orthodontic treatments, not only currently but longitudinally over many years, is very important for improvement of care (24).

Studies indicate a significant improvement in the statistical records of orthodontic treatment at all health care levels, particularly in the private sector. This improves strategic principles for evaluation of this form of health care, which should be available to every child (25). Studies point out the importance of long-term monitoring and constant evaluation of orthodontic treatment, using the same methodology and criteria, because it is only in that way that implementation of this form of health care can be properly evaluated $(26,27)$. Studies conducted in England showed that the great benefit from interventions conducted was maintained after 6 years in $94 \%$ of persons who underwent orthodontic treatment (28).

Many countries have introduced mandatory testing of dental health components to the health care program for children. Studies of dental health components in children aged 10 years in New Zealand showed that one in three examined children needed orthodontic treatment (29). Although the issue of the socio-economic standard of the examined children's families was not included in our study, this issue may be one of the reasons for the great need for orthodontic treatment, due to the generally poor financial income, still felt in the region after the war.

The study by Topic et al. conducted in this area in 1990 on the need for orthodontic treatment showed that $36 \%$ of children aged 6-12 years had occlusal anomalies, of which $30 \%$ required treatment (17). Addi- tionally, Ivankovic et al. established that after the war, in 1999, there was a significantly higher prevalence of orthodontic anomalies, in $55 \%$ of subjects, of which $49 \%$ had a great need for orthodontic treatment (30). Studies of the orthodontic treatment needs of school children aged 12-15 years in Jordan showed that $34-71 \%$ of the subjects needed orthodontic treatment (16). This is approximately equivalent to the results of our study. These countries are similar to ours in terms of economic opportunities, and this information confirms the findings of Antoff et al. that a favorable socioeconomic situation is a precondition for prevention of occlusal defects (31).

The high prevalence rates of dental caries and periodontal diseases (30) in this region have an adverse effect and cause this great need for orthodontic treatment, and are the direct negative etiological factors in occlusal anomalies (15). Unfavorable allocation of resources (staff, premises and equipment) for health care does not allow application of the principle of availability, and it is not fully respected. The high percentage of orthodontic treatment needs in the area of this study is the consequence of the concentration of health resources, which are mostly located in urban centers. Financial resources from the gross domestic product are extremely insufficient in Bosnia and Herzegovina, which also leads to the difficult situation in the field of oral health.

\section{Limitations of the study}

In order to make general conclusions, it is necessary to expand the study area, to conduct the study in several municipalities, and increase the age range of the examined children.

\section{Conclusions}

Our study showed that a high percentage of children have a great need for orthodontic 
treatment. Orthodontic anomalies among the examined children have epidemic proportions, which indicates that oral health care in school children is not available to children in Prozor-Rama. Children's orthodontic care is not available in the Rama Community Health Center in the municipality of Prozor-Rama, while the study showed that orthodontic treatment would be highly acceptable by children with detected orthodontic changes. Therefore, primary health care guidelines should be developed to introduce orthodontic indices into clinical practice, while specialists for orthodontics should be involved to determine orthodontic treatment needs, as well as to provide orthodontic treatment in wellequipped orthodontic clinics.

\section{What is already known on this topic}

Children with orthodontic anomalies may become introvert and avoid social contact, and often these children become the subject of ridicule and teasing by their peers. In determining the prevalence and need for treatment, diagnostics based on standardized criteria are important, in order to identify treatment priorities. This is successfully achieved by the IOTN using the DHC.

\section{What this study adds}

Previous research in Bosnia and Hercegovina failed to use the IOTN according to the DHC, which is now a new standard for categorization of orthodontic treatment. The results will give an insight into the need for orthodontic treatment in school children in the municipality of Prozor-Rama. It is expected that the results of this research will contribute to the improvement of oral health care among school children.

Authors' contributions: Conception and design: RZ and DG; Acquisition, analysis and interpretation of data: RZ, SC and MM; Drafting the article: RZ, MM and DG; Revising it critically for important intellectual content: AĆ, KV and KG. Approved final version of the manuscript: RZ, SC, MM, AĆ, KV and DG.

Conflict of interest: The authors declare that they have no conflict of interest.

\section{References}

1. Angelillo IF, Sagliocco G, Hendricks SJ, Villari P. Tooth loss and dental caries in institutionalized elderly in Italy. Community Dent Oral Epidemiol. 1990;18(4):216-8.

2. Warren J, Bishara E. Duration of nutritive and nonnutritive sucking behaviors and their effects on the dental arches in the primary dentition. Am J Orthod. 2002;121(4):347-56.

3. Chew MT, Aw AK. Appropriateness of orthodontic referrals: self-perceived and normative treatment needs of patients referred for orthodontic consultation. Community Dent Oral Epidemiol. 2002;30(6):449-54.

4. Hassan AH. Orthodontic treatment needs in the western region of Saudi Arabia: a research report. Head Face Med. 2006;2:2.

5. Karjalainen S, Rönning O, Lapinleimu H, Simell O. Association between early weaning, non-nutritive sucking habits and occlusal anomalies in 3 -year-old Finnish children. Int J Paediatr Dent. 1999;9(3):169-73.

6. Larsson E. Sucking, chewing, and feeding habits and the development of crossbite: a longitudinal study of girls from birth to 3 years of age. Angle Orthod. 2001;71(2):116-9.

7. Trottman A, Elsbach HG. Comparison of malocclusion in preschool black and white children. Am J Orthod Dentofacial Orthop. 1996;110(1):69-72.

8. Brunelle JA, Bhat M, Lipton JA. Prevalence and distribution of selected occlusal characteristics in the US population, 1988-1991. J Dent Res. 1996;75 Spec No:706-13.

9. Jacobson A. Psychological aspects of dentofacial esthetics and orthognathic surgery. Angle Orthod. 1984;54(1):18-35.

10. Burden DJ, Pine CM. Self-perception of malocclusion among adolescents. Community Dent Health. 1995;12(2):89-92.

11. Trulsson U, Strandmark M, Mohlin B, Berggren U. A qualitative study of teenagers' decisions to undergo orthodontic treatment with fixed appliance. J Orthod. 2002;29(3):197-204.

12. Nobile CG, Pavia M, Fortunato L, Angelillo IF. Prevalence and factors related to malocclusion and orthodontic treatment need in children and adolescents in Italy. Eur J Public Health. 2007;17(6):637-41.

13. Office for National Statistics. Census $2001 \mathrm{Na}$ tional Report for England and Wales. London: The Stationary Office; 2003.

14. Linder-Aronson S, Bjerrehorn K, Forsberg CM. Objective and subjective need for orthodontic treatment in Stockholm County. Swed Dent J. 2002;26(1):31-40.

15. Tausche E, Luck O, Harzer W. Prevalence of malocclusions in the early mixed dentition 
and orthodontic treatment need. Eur J Orthod. 2004;26(3):237-44.

16. Abdullah MS, Rock WP. Assessment of Orthodontic Treatment Need in 5,112 Malaysian Children Using the IOTN and DAI Indices. Community Dent Health. 2001;18(4):242-8.

17. Topić B. Primary dental care in children in Bosnia and Herzegovina [in Croatian]. In Rajić Z. Editor. Primary Dental Protection, Zagreb: JUMENA; 1989;109-15.

18. Berk NW, Bush HD, Cavalier J, Kapur R, StudenPavlovich D, Sciote J, et al. Perception of orthodontic treatment need: opinion comparisons of orthodontists, pediatric dentists, and general practitioners. J Orthod. 2002;29(4):287-91; discussion 277.

19. Hamdan AM. The relationship between patient, parent and clinician perceived need and normative orthodontic treatment need. Eur J Orthod. 2004;26(3):265-71.

20. Uğur T, Ciğer S, Aksoy A, Telli A. An epidemiological survey using the Treatment Priority Index (TPI). Eur J Orthod. 1998;20(2):189-93.

21. Grzywacz I. The value of the aesthetic component of the Index of Orthodontic Treatment Need in the assessment of subjective orthodontic treatment need. Eur J Orthod. 2003;25(1):57-63.

22. Burden DJ, Pine CM, Burnside G. Modified IOTN: An Orthodontic Treatment Need Index for Use in Oral Health Surveys. Community Dent Oral Epidemiol. 2001;29(3):220-5.
23. Shaw WC. The influence of children's dentofacial appearance on their social attractiveness as judged by peers and lay adults. Am J Orthod. 1981;79(4):399-415.

24. Harrison JE. Evidence-based orthodontics: where do I find the evidence? J Orthod. 2000;27(1):71-8.

25. Cannavina CD, Cannavina G, Walsh TF. Effects of evidence-based treatment and consent on professional autonomy. Br Dent J. 2000;188(6):302-6.

26. Birkeland K, Bøe OE, Wisth PJ. Relationship between occlusion and satisfaction with dental appearance in orthodontically treated and untreated groups. A longitudinal study. Eur J Orthod. 2000;22(5):509-18.

27. Cooper S, Mandall NA, DiBiase D, Shaw WC. The reliability of the Index of Orthodontic Treatment Need over time. J Orthod. 2000;27(1):47-53.

28. Linklater R, Fox N. The long-term benefits of orthodontic treatment. British Dental Journal. 2002;192(10):583-7.

29. Crowther P, Harkness M, Herbison P. Orthodontic treatment need in 10-year-old Dunedin schoolchildren. N Z Dent J. 1997;93(413):72-8.

30. Ivanković A, Leko M, Radić A, Vukić I, Kljakić S, Ivanković Z. Epidemiology of the most common oral diseases in the counties of Croatian politicalterritorial areas of the Federation of $\mathrm{BiH}$. [in Croatian]. Mostariensia. 1999;10:43-9.

31. Antoff E. Social inequality and orthodontic treatment. Aust Dent J. 2000;2:23-6. 